\title{
Modeling of the radiation regime and photosynthesis of a finite canopy using the DART model. Influence of canopy architecture assumptions and border effects
}

\author{
Valérie Demarez*, Jean-Philippe Gastellu-Etchegorry, Patrick Mordelet, \\ Claude ToscA, Georges MarTy, Pierre GuILleviC
}

CESBIO, 8, avenue Edouard Belin, 31055 Toulouse, France

(Received 14 May 1999; revised 2 November 1999; accepted 27 January 2000)

\begin{abstract}
The scope of this work was to investigate the impact of the border effects and the 3-D architecture of a fallow field on: 1) its bidirectional reflectance factor (BRF); 2) its PAR (photosynthetically active radiation) regime; and, to a lesser extent, 3) on its carbon assimilation. For this purpose, laboratory BRF measurements were conducted on a sample of a fallow field. Moreover, we modified a 3-D radiative transfer model in order to simulate the visible and near infrared BRF of finite and heterogeneous media. Several scene representations were used (finite and infinite scenes with/without 1-D or 3-D distribution of leaf area index [LAI]). Results showed that border effects and LAI distribution strongly affect the BRF, with variations as large as $40 \%$ depending on the scene representations and on the spectral domain. PAR profiles and instantaneous canopy carbon assimilation of an infinite scene (natural conditions) were also studied with the 3-D model. The results stressed that, in the case of a fallow field, the use of a simple LAI profile provides enough information to accurately simulate the effects of the architecture on the PAR regime and the carbon assimilation of a fallow field.
\end{abstract}

border effect / 3-D architecture / BRF / PAR / fallow field

Résumé - Modélisation du transfert radiatif et de l'activité photosynthétique d'un milieu fini avec le modèle DART. Étude de l'influence de l'architecture du couvert et des effets de bords. L'objectif de ce travail était d'étudier l'influence des effets de bord et de l'architecture d'un couvert de jachère sur : 1) le facteur de réflectance bidirectionnel (FRB) ; 2) la distribution du PAR (rayonnement photosynthétiquement actif) ; et, dans une moindre mesure, 3) l'assimilation carbonée, $\mathrm{A}\left(\mathrm{CO}_{2}\right)$. Nous avons, pour cela, utilisé un modèle de transfert radiatif 3-D (DART) que nous

Communicated by Gérard Guyot (Avignon, France)

* Correspondence and reprints

demarez@cesbio.cnes.fr 
avons adapté de manière à pouvoir simuler le FRB, dans le visible et le proche infrarouge, de milieux de dimension finie et étudier ainsi les effets de bord. Plusieurs représentations du milieu (maquettes finies et infinies avec un LAI constant, profil vertical de LAI et distribution 3-D de LAI) ont été utilisées afin de tester l'influence de l'architecture du couvert sur le FRB. L'analyse des résultats a permis de montrer que les effets de bords ainsi que la distribution du LAI influençaient fortement le FRB (variations supérieures à $40 \%$ ). Les simulations ont été comparées à des mesures de réflectances bi-directionnelles réalisées en laboratoire sur un échantillon de jachère prélevé sur le terrain. Des profils de PAR (rayonnement photosynthétiquement actif) et d'assimilation carbonée instantanés ont également été simulés dans le cas d'un milieu naturel (de dimension infinie). Il s'est avéré que, dans le cas d'une jachère, l'utilisation d'un simple profil de LAI permettait de prendre en compte l'effet de l'architecture sur le PAR et sur l'assimilation carbonée.

effet de bord / architecture 3-D / FRB / PAR / jachère

\section{Introduction}

The radiation regime within canopies, and more especially the photosynthetically active radiation (PAR) domain, determines the mass and energy exchange with the atmosphere. Indeed, PAR absorption provides energy input for the tightly linked carbon, nitrogen and water cycles and plays an essential role in dry matter production (NPP: net primary productivity). Optical remote sensing, i.e., the measurement of surface reflectance, offers an interesting alternative to in situ measurements of the vegetation radiation regime. It has become the basic tool whenever studies are conducted over different dates and large areas. Many studies have already emphasized the great potential of this technique for studying vegetation structural characteristics $[4,5,9,22,23,25]$, and functioning processes through the determination of a quantity such as absorbed photosynthetically active radiation (APAR) or chlorophyll content [1, 2, 6, 8, 18, 21]. However, the results of these studies are often disappointing because they rely on empirical relationships that are not robust in time and space. Moreover, the variability in these relationships is often difficult to explain and predict.

A clear understanding of the physics of directional reflectance variations of vegetation in the optical wavelengths is necessary to improve vegetation characteristics extraction techniques from remote sensing data. This includes the normalization of satellite data acquired under different configurations, the determination of the optimal configuration of acquisitions, and obviously the development of reliable relationships between radiometric measurements from space and the physical and biological characteristics of the biosphere. In this context, radiative transfer models are key tools to improve our knowledge, especially if they can simultaneously simulate vegetation bidirectional reflectance factor (BRF) and PAR regimes for given vegetation characteristics (leaf area index [LAI], chlorophyll, architecture). First, modeling investigations were conducted with rather simple models, i.e., turbid medium based canopy models [13-15, 27]. However, a major limitation of the turbid medium models is that they do not account for some canopy architecture variables such as tree crown closure, tree density, tree height, shape and dimension of crowns, which may imply wrong estimation of forest PAR and BRF [11]. The recent availability of 3-D models [10, 17, $19,20]$ allows one to account for the influence of canopy architecture on reflectance.

The first part of this paper consists of an analysis of the influence of canopy border effects and spatial heterogeneity on the BRF of a fallow field using a 3-D radiative transfer model: the DART [10] model. This model was used as it accounts for detailed canopy architecture. However, in this study, the DART model had to be adapted to simulate radiative transfer within finite media. Indeed, similarly to commonly available models, DART assumes that the medium is infinite. The BRF simulations were compared to laboratory BRF measurements of a fallow field.

In the second part, simulations were also conducted in order to study the effect of the spatial 
heterogeneity on the PAR and the carbon assimilation of an actual fallow field, i.e., an infinite vegetation cover.

\section{Materials and methods}

\subsection{Vegetation species}

Measurements were conducted in the laboratory on a fallow field sample in June 1997. The sample was collected at the MUREX site [3]. The latter is a dense close herbaceous agricultural field, with various species such as Potentilla reptans, Brachypodium ramosum, Geranium rotundifolium, Erigeron canadensis and Rumex acetosa. Although their proportions vary throughout the year, $P$. reptans and to a lesser extent $B$. ramosum are the dominant species. In February 1997, a sample $(0.55 \times 0.45 \mathrm{~m})$ was collected from the field and put in a tub (Fig. 1) for further laboratory measurements. The LAI $(=3)$ of this sample was made up of about $80 \%$ P. reptans and $20 \%$ B. ramosum, similarly to the mean field proportions.

\subsection{Canopy architecture}

The 3-D architecture of the central part of the sample $(25 \mathrm{~cm}$ long $\times 25 \mathrm{~cm}$ wide $\times 70 \mathrm{~cm}$ high $)$

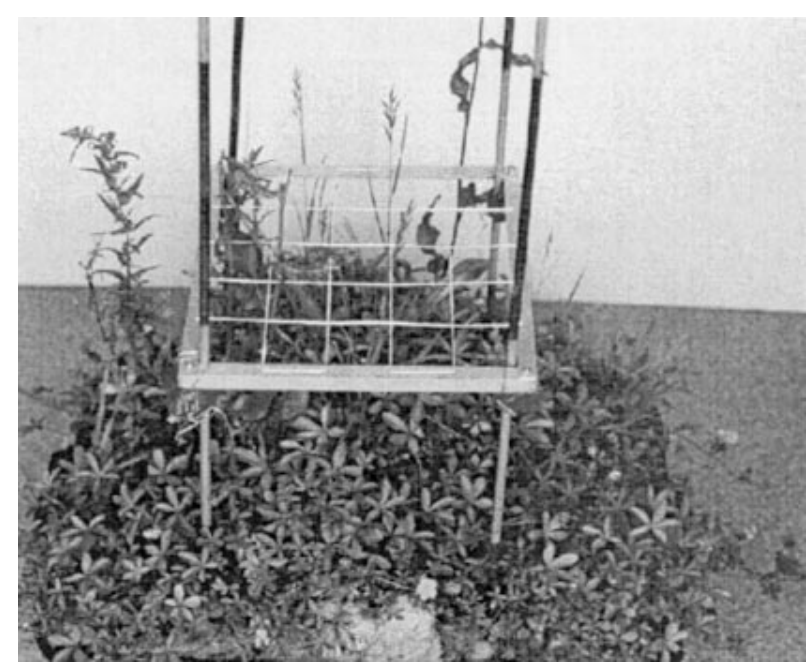

Figure 1. Sample measured in the laboratory. The grid was used to assess the 3-D architecture of the sample.

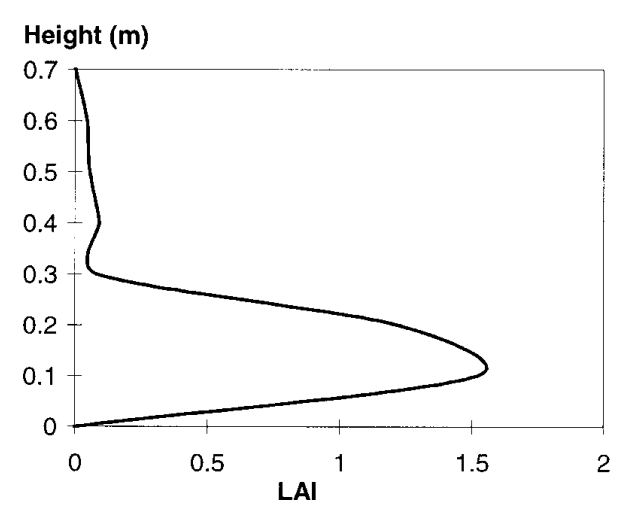

Figure 2. LAI vertical profile of the sample (Fig. 1).

was measured using a grid sub-divided into elementary cells $(5 \mathrm{~cm}$ long $\times 5 \mathrm{~cm}$ wide $\times 10 \mathrm{~cm}$ high) (Fig. 1). For each cell, the species composition and the LAI were determined. The leaf area was assessed using a scanner. Measurements showed that the leaf angle distribution (LAD) was predominantly planophile (mean inclination $=26^{\circ}$ ) for $P$. reptans, and spherical for $B$. ramosum. The major part of the LAI was concentrated in the first $30 \mathrm{~cm}$ (Fig. 2).

\subsection{Leaf optical properties}

Leaf optical properties, i.e., hemispheric reflectance and transmittance, were measured with an Eotech spectrometer (an ETA optic spectrometer, Germany, model CSS-12) and an integrating sphere. The Eotech operates between 500 and 900 $\mathrm{nm}$ with a spectral resolution equal to $1.1 \mathrm{~nm}$. Leaves of $P$. reptans and $B$. ramosum showed typical reflectance and transmittance spectra between 500 and $900 \mathrm{~nm}$ (Fig. 3).

\subsection{Measured BRF}

\subsubsection{Vegetation}

Reflectances of the sample were measured with the Eotech spectrometer fixed to a laboratory goniometer made of two rotating arches of 2.4 and $2.8 \mathrm{~m}$ diameter, respectively (Fig. 4). 

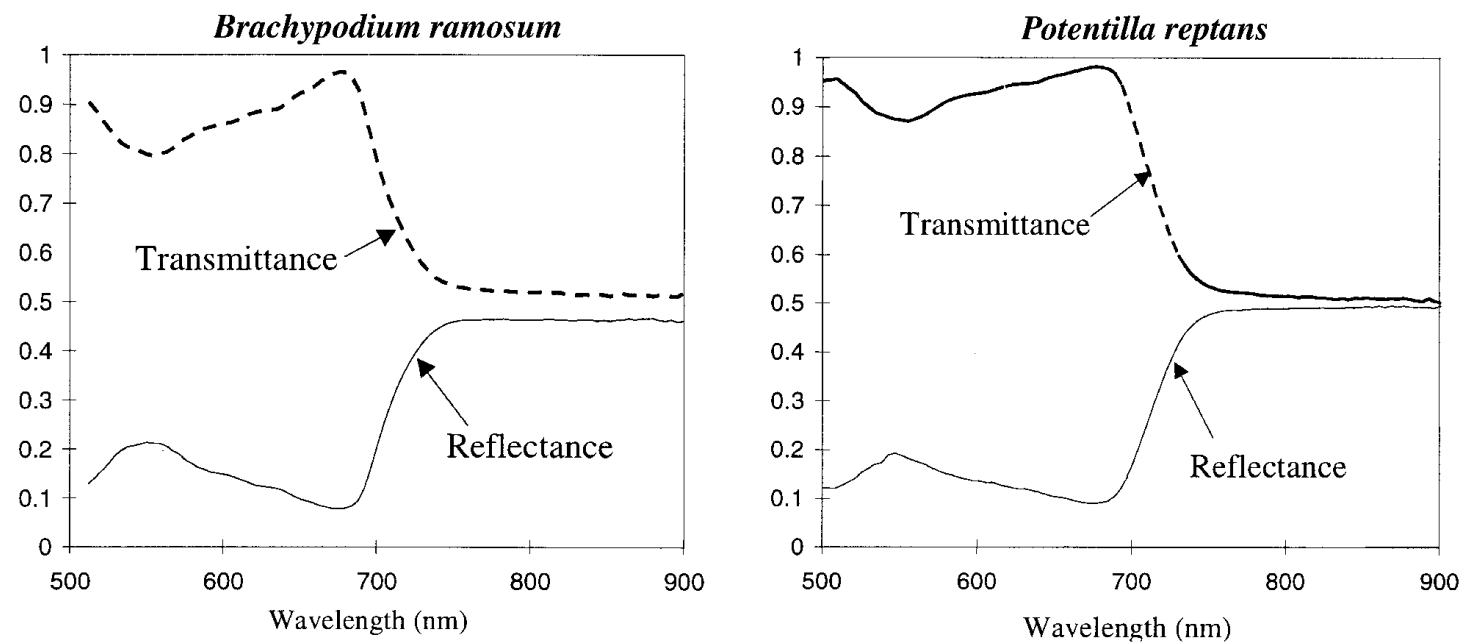

Figure 3. Reflectance $\left(\rho_{\mathrm{f}}\right)$ and transmittance $\left(\tau_{\mathrm{f}}\right)$ spectra of Potentilla reptans and Brachypodium ramosum. Spectra are the mean of 5 spectra of different leaves, in order to improve the signal to noise ratio.

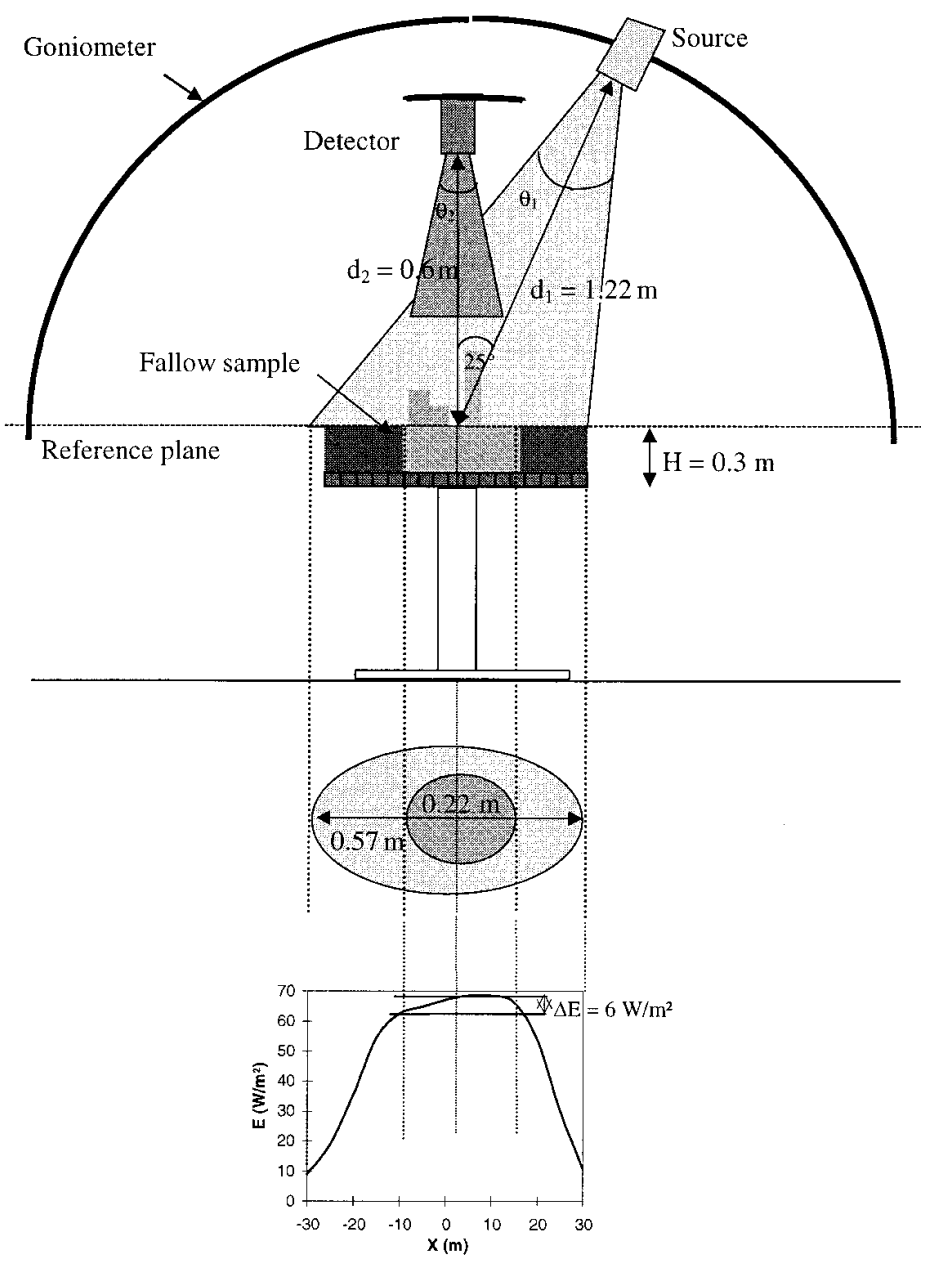

Figure 4. Protocol of measurements performed in the laboratory with the goniometer $\left(\theta_{1}=\theta_{2}=25^{\circ}\right)$. 
The sample was located in the center of the goniometer. The source of illumination was a quartz tungsten halogen (QTH, $250 \mathrm{~W})$ collimated lamp. Because of the spatial extent of the sample and the small distance between the source and the target $\left(\mathrm{d}_{1}=1.22 \mathrm{~m}\right)$, the lamp was partly uncollimated to illuminate the sample fully while minimizing the illumination angle $\left(\theta_{1}\right)$. The latter was fixed at a $25^{\circ}$ angle, which corresponds to an illuminated spot of $0.57 \mathrm{~m}$ in diameter.

The reference (Spectralon) used to calculate the BRF was positioned in the horizontal reference plane (Fig. 4).

The detector was moved along the arches in order to measure the BRF in the principal and perpendicular planes for five viewing zenith angles: $-40^{\circ},-20^{\circ}, 0^{\circ},+20^{\circ}$ and $+40^{\circ}$. The size of the viewed areas varied between $0.22 \times 0.22 \mathrm{~m}$ for a nadir viewing zenith angle, and $0.28 \times 0.28 \mathrm{~m}$ with a $40^{\circ}$ viewing zenith angle.

Due to experimental constraints, reflectances in the hot spot configuration could not be measured.

\subsubsection{Bare soil}

The soil spectral BRF was measured using the same protocol immediately after the vegetation was cut. At all wavelengths the reflectance of the soil was quite Lambertian. Thus, for simulations, we simply used the reflectance measured at nadir (Fig. 5).

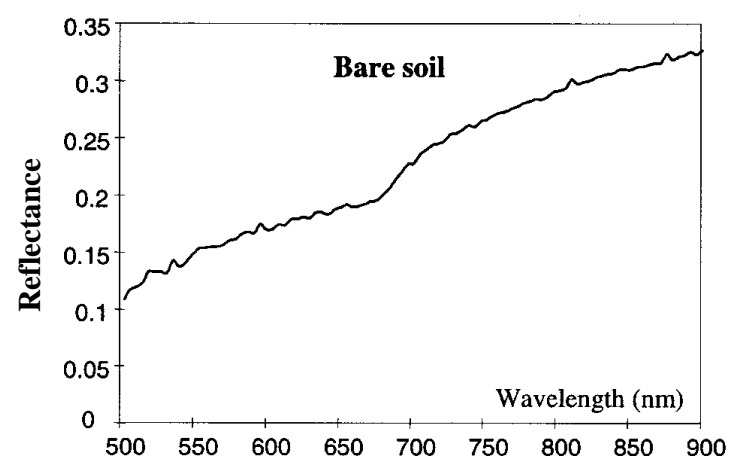

Figure 5. Soil reflectance spectra (average of 5 samples).

\subsection{BRF modeling}

The DART model simulates BRF, directional images and the 3-D distribution of APAR and transmitted PAR. It operates on discrete 3-D scene representations. These are rectangular cell matrices that may include any distribution of trees, grass, water and soil surfaces, with the possible presence of anisotropic atmosphere, topography, etc. The illumination scheme consists of an array of sources superimposed on the top of the scene representation. Radiation propagation is tracked by the discrete ordinate method. Similarly to most commonly used models such as the SAIL model [27], the DART model assumes that the scene where radiation propagates is infinite. For that, the radiation that crosses a vertical plane of the cell matrix is recast from the opposite plane, at the same trajectory angle with the same energy and direction. This is an erroneous assumption with laboratory measurements, as in that case, the observed scene is finite. This implies that the radiation regime is not the same for all points of any horizontal plane. To take this effect into account, radiation should not cross the vertical planes that bound the scene representation. Two different solutions could be used to prevent radiation from re-entering the scene: to modify the DART model, or to modify the scene representation. The second solution was adopted. It simply consisted of bounding the scene by an opaque wall. Moreover, this wall was black in order to avoid any backward scattering of radiation exiting the scene (Fig. 6).

The finite size of the illuminated spot, which was smaller than the size of the entire scene, was another source of difficulty. This implied adapting the illumination scheme of the DART model to the actual illumination scheme. Instead of considering an array of sources regularly distributed on top of the scene representation, sources occupied a more restricted surface, which permitted only part of the scene to be illuminated (Fig. 6).

Finally, the last difficulty involved the variation of the viewed area with the viewing angle: both increased simultaneously. This is not important if the scene is infinite and homogeneous, and if the scene illumination pattern is the same everywhere. 


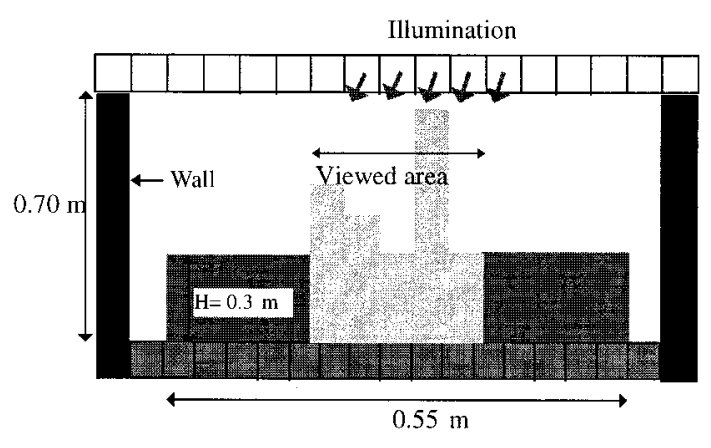

Figure 6. Lateral view of the 3-D finite scene representation of the sample. The light gray surface shows the part of the sample where the 3-D LAI distribution was measured. The remaining part of the sample is shown in dark gray. Opaque walls bound the scene.

However, under actual experimental conditions this is an important source of error. This trend, combined with the limited spatial extent of the illumination spot, implies that if the sensor is more tilted, it tends to view less illuminated areas, which implies a decrease of the measured BRF. This decreasing trend is only due to the experimental configuration. Thus, it must be accounted for to establish reliable comparisons between measured and simulated BRF.

As the 3-D distribution of LAI was determined only for the central part of the sample, some assumptions were made concerning the vegetation cover that surrounded it. This was represented as a homogeneous cover with a height $(0.3 \mathrm{~m})$ and LAI (3.0) equal to the mean measured values (Fig. 6). Five different representations of the sample were used to analyze how the scene dimensions and heterogeneity influence the BRF: 1) turbid infinite: the scene is divided into 10 layers with similar LAI (= 0.3) and LAD (planophile); 2) turbid finite: this corresponds to scene (1) with an opaque wall all around it; 3) 1-D infinite: this corresponds to scene (1) with the measured vertical LAI profile (Fig. 2) of the sample; 4) 3-D infinite: this corresponds to an infinite juxtaposition of the sample. Each cell has the LAI, LAD and optical properties actually measured; 5) 3-D finite: this corresponds to scene (4) with an opaque wall all around it. It is the most realistic scene representation.
Table I. Measured characteristics of the sample: LAI, LAD for each species, and leaf and soil optical properties (reflectance and transmittance) in the green, red and near infrared (NIR).

\begin{tabular}{|c|c|c|}
\hline & 3-D scene & Turbid scene \\
\hline LAI & $\begin{array}{c}3 \\
\text { (Variable LAI } \\
\text { per cell) }\end{array}$ & $\begin{array}{c}3 \\
(\mathrm{LAI}=0.3 \\
\text { per cell })\end{array}$ \\
\hline LAD & $\begin{array}{c}\text { Planophile (Potentilla reptans) } \\
\text { Spherical (Brachypodium } \\
\text { ramosum) }\end{array}$ & Planophile \\
\hline $\begin{array}{l}\rho_{\mathrm{f}} \tau_{\mathrm{f}} \\
\text { Green } \\
\text { Red } \\
\text { NIR }\end{array}$ & $\begin{array}{l}0.20 / 0.15 \\
0.10 / 0.10 \\
0.50 / 0.48\end{array}$ & \\
\hline $\begin{array}{l}\text { Dry soi } \\
\text { Green } \\
\text { Red } \\
\text { NIR }\end{array}$ & l: $\rho_{\text {soil }}$ & \\
\hline
\end{tabular}

The same input parameters were used for the 5 scene representations (Tab. I) in order to stress the impact of vegetation heterogeneity on reflectance. Leaf optical properties displayed a natural variability that was represented by a mean and a standard deviation. The variability of the simulated BRF associated to extreme values (mean \pm one standard deviation) of leaf optical properties is represented by bars in Figure 7. In fact, we used leaf optical properties that were within the bounds 'mean \pm one standard deviation' and such that 3-D finite simulations fitted to the nadir measured reflectances. This explains the perfect agreement between 3-D finite simulations and measurements at nadir. The possibility to find convenient leaf optical properties for all spectral bands was considered to be very encouraging. Results obtained with the other cases (turbid, 1-D and 3-D infinite), using the same input parameters, showed poor agreement with the measurements.

\subsection{Simulations of PAR and photosynthesis}

The influence of 3-D architecture on the PAR regime and on the instantaneous photosynthetic 

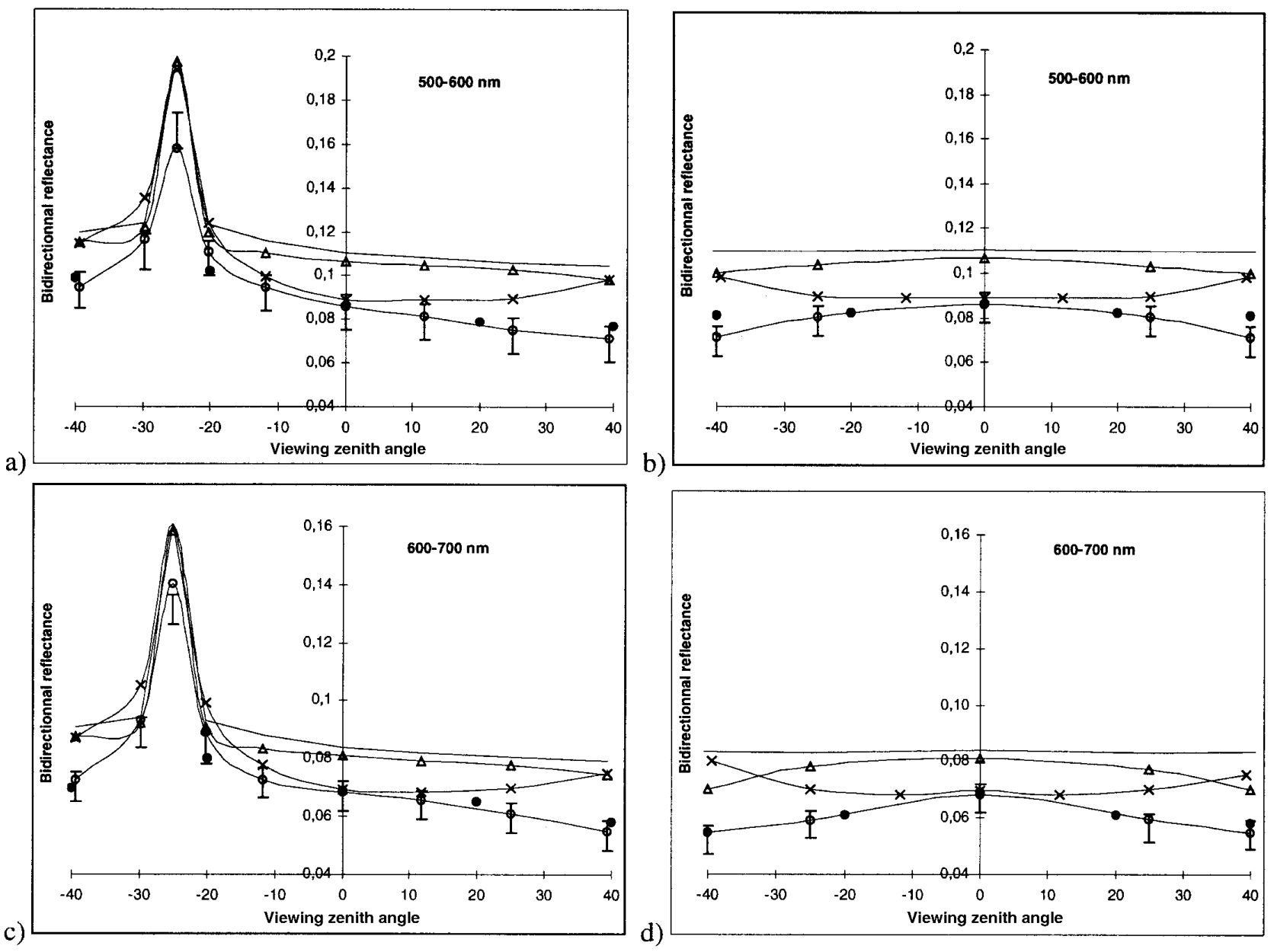

b)
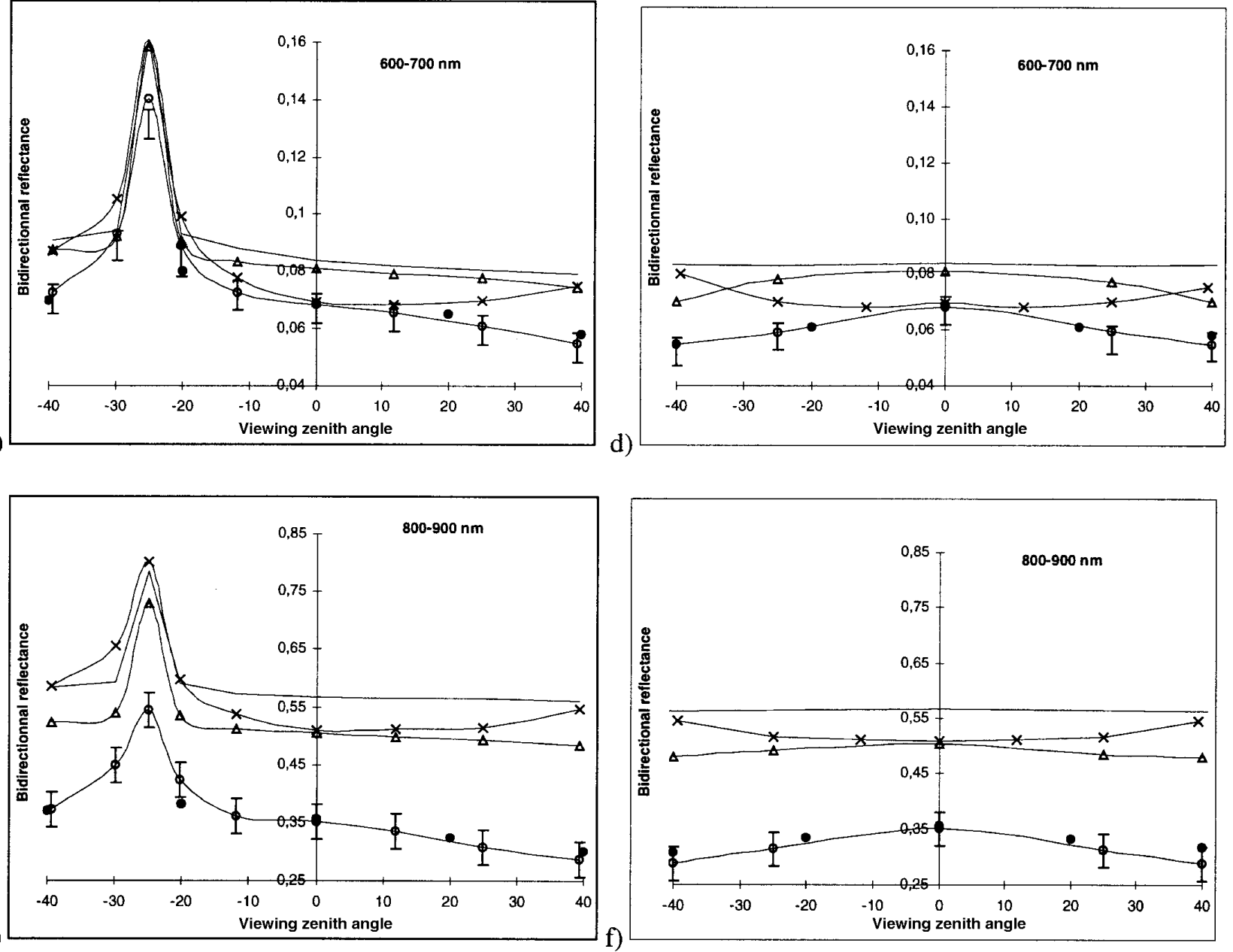

Figure 7. Measured and simulated reflectances of the sample in the principal $(\mathbf{a}, \mathbf{c}, \mathbf{e})$ and perpendicular $(\mathbf{b}, \mathbf{d}, \mathbf{f})$ planes, in the green, red and NIR. The illumination zenith angle is $25^{\circ}$. Bars on the 3-D curves represent the sensitivity of the BRF to the natural variability of leaf optical properties (mean \pm one standard deviation); $(\bullet)$ measurements, $(-\circ) 3$-D finite; $\left({ }_{-}\right) 3$-D infinite; $(\rightarrow)$ turbid finite; (-) turbid infinite. 
activity of a fallow field was analyzed thanks to the 3-D infinite scene used to represent field conditions. Here the conditions were no longer laboratory experimental, but natural conditions (infinite medium). The DART simulations provided both 3-D and 1-D distribution of the foliar absorbed photosynthetically active radiation (APAR) and transmitted PAR. The use of 3-D APAR with a leaf photosynthesis model [7] allowed us to calculate the $\mathrm{CO}_{2}$ assimilation. An essential parameter of the photosynthesis leaf model, i.e., $\mathrm{V}_{\mathrm{m}}$ (the catalytic capacity of the $\mathrm{CO}_{2}$-fixing enzyme, Rubisco) was computed under the assumption that it is proportional to the mean foliar APAR over the last 2-3 weeks, and to a maximum value of $\mathrm{V}_{\mathrm{m}}\left(\mathrm{V}_{\text {max }}\right)$. This computation with the DART model is intended to simulate the influence of the 3-D cover heterogeneity on the spatial $\mathrm{V}_{\mathrm{m}}$ distribution. It must be kept in mind that all transmitted PAR profiles of the 3-D scenes shown later are for cells containing leaves only. They do not account for PAR propagation through empty cells: they correspond to the irradiance of illuminated horizontal surfaces.

The photosynthesis model was run for each cell. This gave the 3-D distribution of the carbon assimilation, $\mathrm{A}\left(\mathrm{CO}_{2}\right)$. The carbon assimilation of the cover was simply computed as the spatial integration of $\mathrm{A}\left(\mathrm{CO}_{2}\right)$.

Here, the leaf temperature was set at $300 \mathrm{~K}$, and the relative humidity at the leaf surface was set at 0.5 . As no measurement of $\mathrm{V}_{\max }$ was available, we used the value of Sellers et al. [24] for $\mathrm{V}_{\max }$ : $50 \mu \mathrm{mol} \mathrm{CO}{ }_{2} \cdot \mathrm{m}^{-2} \cdot \mathrm{s}^{-1}$. Simulations were conducted with sun zenith angles equal to 25 and $50^{\circ}$.

\section{Results and discussion}

\subsection{Comparison between measured and simulated BRF}

In the principal and perpendicular planes, in the forward direction, the measured reflectances decrease for view zenith angles from $\theta_{\mathrm{v}}=0^{\circ}$ to $40^{\circ}$, in the three spectral domains (Fig. 7). One explanation for this discrepancy is that reflectances are usually simulated with radiation propagation media of infinite spatial extent, conversely to laboratory conditions. In an infinite medium, the radiation regime at any point within a horizontal plane is constant, contrary to the case of a finite medium.

Due to instrumental constraints, the peak of the hot spot could not be measured but was simulated and appears clearly in the principal plane for $\theta_{\mathrm{v}}=$ $25^{\circ}$ in all simulations.

Major results concerning BRF simulations are briefly commented upon below.

- Turbid infinite scene: apart from the hot spot, reflectances are rather isotropic and larger than the measured reflectances. Indeed, radiative transfer in turbid media neglects local shadowing effects.

- Turbid finite scene: compared to the turbid infinite scene, the finite medium results in a very small relative reflectance decrease in the visible and a relative $10 \%$ decrease in the near infrared. Indeed, the finite extent of the scene implies that the scene is not homogeneously illuminated. Consequently, if the viewing zenith angle increases, the reflectance tends to decrease since the fraction of area less illuminated increases.

- 1-D infinite scene: results are similar to the turbid infinite scene, so that they are not plotted on the graph.

- 3-D infinite scene: compared to the turbid infinite scene, taking into account the canopy architecture implies a $10 \%$ nadir reflectance decrease both in the visible and in the near infrared. However, differences between measured and simulated reflectances are large. Moreover, reflectance increases with the view zenith angle, conversely to measurements.

- 3-D finite scene: compared to the 3-D infinite scene, the finite medium results in a $7 \%$ nadir reflectance decrease in the visible domain and in a $47 \%$ decrease in the near infrared. The use of a finite scene representation modifies the shape of the FRB: conversely to the 3-D infinite scene and similarly to FRB measurements, reflectance decreases with an increase of the viewing zenith angle. The relative reflectance decrease is larger than that of the turbid finite scene. It is about $25 \%$ 
in the green, $20 \%$ in the red and $44 \%$ in the near infrared. Mean relative reflectance difference between 3-D finite simulations and measurements is less than $2 \%$ in all spectral domains.

\subsection{Simulated PAR regime and photosynthesis}

PAR profiles (Fig. 8) are discussed below for each case.

- Turbid infinite scene: the PAR decreases exponentially with height from $400 \mathrm{~W} \cdot \mathrm{m}^{-2}$ at the top of the scene to about $40 \mathrm{~W} \cdot \mathrm{m}^{-2}$ at the bottom of the scene. The zenith illumination angle $\theta_{\mathrm{s}}$ plays a minor role due to the fact that the leaves are horizontal.

- 1-D infinite scene: the PAR variation with height does not describe a simple exponential function. It depends directly on the LAI vertical profile (Fig. 2), with the smaller decrease above the first $20 \mathrm{~cm}$ where leaf density is minimal. The PAR was systematically larger in the 1-D infinite scene than in the turbid infinite scene, although leaf optical properties and LAI are similar in both cases. In fact, the 1-D and turbid infinite scenes intercept the same PAR: for both of them, the total canopy absorbed PAR is equal to $320 \mathrm{~W} \cdot \mathrm{m}^{-2}$.

-3-D infinite scene: above $0.30 \mathrm{~m}$, the PAR is lower for the 3-D scene than for the 1-D scene, and the opposite is observed below $30 \mathrm{~cm}$. Moreover, in the upper part of the scene, the PAR of the 3-D scene does not decrease systematically with height. These trends are due to the 3-D heterogeneity of the scene: compared to the case of the 1-D scene, leaf clumping implies a local decrease of the PAR incident on leaves within the clump, and a larger PAR downwards transmission out of the clump. Contrary to other cases, the PAR is influenced by the zenith angle. At soil level, the incident PAR is equal to $50 \mathrm{~W} \cdot \mathrm{m}^{-2}$ for $\theta_{\mathrm{s}}=50^{\circ}$ and $75 \mathrm{~W} \cdot \mathrm{m}^{-2}$ for $\theta_{\mathrm{s}}=25^{\circ}$ which is larger than that of the 1-D scene $\left(=40 \mathrm{~W} \cdot \mathrm{m}^{-2}\right)$. For $25^{\circ}$, the total $3-\mathrm{D}$ canopy absorbed PAR is $305 \mathrm{~W} \cdot \mathrm{m}^{-2}$ instead of $320 \mathrm{~W} \cdot \mathrm{m}^{-2}$ for the 1-D scene. The PAR absorbed by the soil is equal to $60 \mathrm{~W} \cdot \mathrm{m}^{-2}$ instead of $30 \mathrm{~W} \cdot \mathrm{m}^{-2}$ for the $1-\mathrm{D}$ scene.

Although the simulated 1-D and 3-D PAR profiles differ, the total net $\mathrm{CO}_{2}$ assimilation is nearly the same for the 1-D and the 3-D scenes (Tab. II

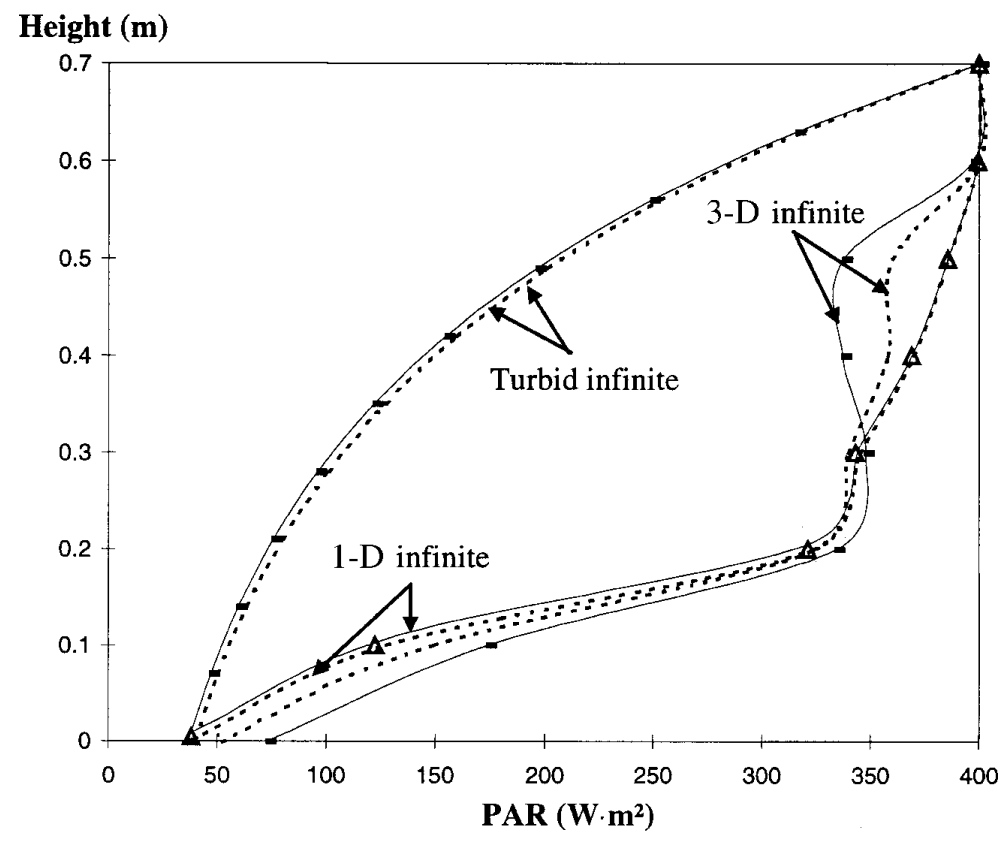

Figure 8. Transmitted PAR profiles of a fallow field for the turbid, 1-D and 3-D scenes. Illumination zenith angles are $25^{\circ}$ and $50^{\circ}$. Canopy LAI is 3 . Incident solar constant in the PAR domain is $400 \mathrm{~W} \cdot \mathrm{m}^{-2}$. ( - $) 25^{\circ}$ turbid infinite; ( ...... $50^{\circ}$ turbid infinite; $(\leftrightharpoons)$ ) $25^{\circ} 1$-D infinite; $(\cdots \bowtie . \cdot) 50^{\circ}$ 1-D infinite; (- $25^{\circ}$ 3-D infinite; (...... $50^{\circ} 3$-D infinite. 


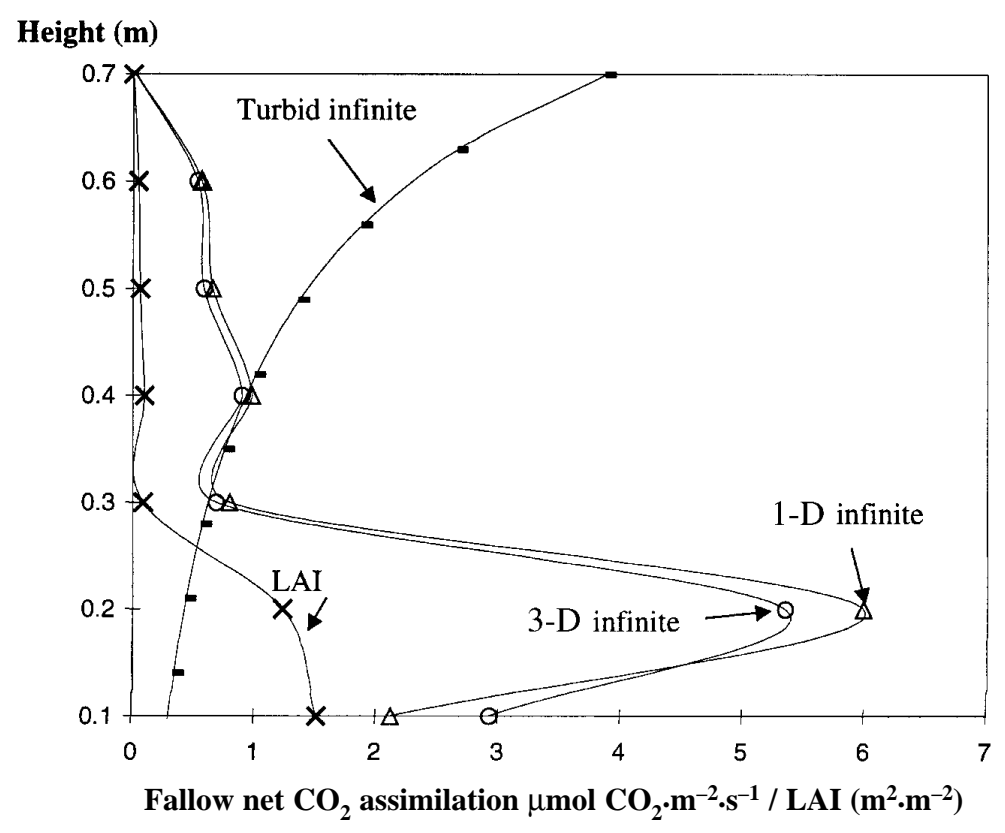

Figure 9. Fallow field net $\mathrm{CO}_{2}$ assimilation profile simulated for the turbid, 1-D and 3-D infinite scenes. The illumination zenith angle is $25^{\circ}$; $(-) 25^{\circ}$ turbid infinite; $\left(-{ }_{-}\right) 25^{\circ} 3-\mathrm{D}$ infinite; $\left(\triangleleft_{-}\right) 25^{\circ} 1$-D infinite; $\left({ }_{\star}\right)$ LAI:
Table II. Total $\mathrm{CO}_{2}$ assimilation $\left(\mu \mathrm{mol} \mathrm{CO} \cdot \mathrm{m}^{-2} \cdot \mathrm{s}^{-1}\right)$ of the turbid, 1-D and 3-D scenes.

Turbid infinite 1-D infinite 3-D infinite

\begin{tabular}{llll}
\hline$\theta_{\mathrm{s}}=25^{\circ}$ & 13 & 11 & 11 \\
$\theta_{\mathrm{s}}=50^{\circ}$ & 13 & 11 & 11 \\
\hline
\end{tabular}

and Fig. 9). This suggests that, in the case of a fallow field, a simple 1-D LAI profile provides enough information to simulate $\mathrm{CO}_{2}$ assimilation. On the other hand, the total $\mathrm{CO}_{2}$ assimilation of the turbid scene departed from that of the 1-D and 3-D scenes: it was $18 \%$ larger (Tab. II), which is consistent with the fact that the absorbed PAR of the turbid scene is larger than that of the 3-D scene. The local $\mathrm{CO}_{2}$ assimilation depends on the absorbed PAR intensity and LAI. This explains why the vertical $\mathrm{CO}_{2}$ assimilation profile is similar to the LAI profile except for the lower layer $(<20 \mathrm{~cm})$ where the PAR becomes a limiting factor for the photosynthesis, due to radiation absorption by the upper layers $(>20 \mathrm{~cm})$.

\section{Concluding remarks}

Results show that, in laboratory conditions, border effects and canopy architecture strongly influence canopy BRF. For example, neglecting detailed canopy architecture features such as finite extent and 3-D structure lead to about $40 \%$ BRF overestimation. Because of instrumental constraint (small distance between the source and the target, vertical extension of the canopy, and uncollimated source), the measured reflectance values depend on the characteristics (height, size, etc.) of our sample. For this reason, conclusions that concern BRF could not be generalized to field measurements. The next step should be to investigate and quantify these effects in natural conditions.

Canopy PAR transmittance and $\mathrm{CO}_{2}$ assimilation were simulated in order to investigate their sensitivity to natural vegetation architecture (1-D and 3-D LAI distribution). Preliminary results indicated that, in the case of a fallow field, the use of a simple vertical LAI profile was sufficient to accurately represent the vegetation photosynthetic activity. The simulated values of canopy 
assimilation $\left(11 \mu \mathrm{mol} \mathrm{CO} \mathrm{CO}_{2} \cdot \mathrm{m}^{2} \cdot \mathrm{s}\right)$ were favorably compared with measurements performed in the frame of the MUREX project (i.e., between 5 and $\left.15 \mu \mathrm{mol} \mathrm{CO} \cdot \mathrm{m}^{2} \cdot \mathrm{s}\right)$ [3].

\section{References}

[1] Asrar G., Myneni R.B., Choudhury B.J., Spatial heterogeneity in vegetation canopies and remote sensing of absorbed photosynthetically active radiation: a modeling study, Remote Sens. Environ. 41 (1992) 85-103.

[2] Bégué A., Leaf area index, intercepted photosynthetically active radiation and spectral vegetation indices: a sensitivity analysis for regular clumped canopies, Remote Sens. Environ. 46 (1993) 45-59.

[3] Calvet J.C., Bessemoulin P., Berne C., Braud I., Courault D., Fritz N., Gonzalez-Sosa E., Goutorbe J.P., Haverkamp R., Jaubert J., Kergoat L., Lachaud G., Laurent J.P., Mordelet P., Noilhan J., Olioso A., Peris P., Roujean J.L., Thony J.L., Tosca C., Vauclin M., Vignes D., MUREX: a land-surface field experiment to study the annual cycle of the energy and water budgets, Ann. Geophys. 17 (1999) 838-854.

[4] Carlson T.N., Ripley D.A., On the relation between NDVI, fractional vegetation cover and leaf area index, Remote Sens. Environ. 62 (1997) 214-252.

[5] Chen R., Jupp D.L.B., Woodcock C.E., Strahler A.H., Nonlinear estimation of scene parameters from digital images using zero-hit run-lenght statistics, IEEE Trans. Geosci. Remote Sens. 31:3 (1993)735-746.

[6] Christensen S., Goudriaan J., Deriving light interception and biomass from spectral reflectance ratio, Remote Sens. Environ. 43 (1993) 87-95.

[7] Collatz G.J., Ball J.T., Grivet C., Berry J.A., Physiological and environmental regulation of stomatal conductance, photosynthesis and transpiration: a model that includes laminar boundary, Agric. For. Meteorol. 54 (1991) 107-136.

[8] Demarez V., Modélisation du transfert radiatif et télédétection hyperspectrale pour le suivi temporel de la teneur en chlorophylle d'une forêt tempérée, thèse, Univ. Paul Sabatier Toulouse III, 1997, pp. 142.

[9] Estève P., Inversion du modèle de transfert radiatif DART, thèse, Univ. Paul Sabatier Toulouse III, 1998, pp. 137.

[10] Gastellu-Etchegorry J.P., Demarez V., Pinel V., Zagolski F., Modeling radiative transfer in heteroge- neous 3-D vegetation canopies, Remote Sens. Environ. 58 (1996) 131-156.

[11] Gastellu-Etchegorry J.P., Guillevic P., Zagolski F., Demarez V., Trichon V., Deering D., Leroy M., Modeling BRF and radiation regime of tropical and boreal forests - Part I: BRF, Remote Sens. Environ. June 1999.

[12] Guillevic P., Gastellu-Etchegorry J.P., Modeling $\mathrm{BRF}$ and radiation regime of tropical and boreal forests - Part II: PAR., Remote Sens. Environ. June 1999.

[13] Hobson P., Barnsley M., Analyses of a coupled leaf (PROSPECT) and canopy (SAIL) reflectance model, RSS96: remote sensing in science and industry, Remote Sensing Soc., Univ. Nottingham, UK, 1996, pp. 87-93.

[14] Jacquemoud S., Inversion of the PROSPECT + SAIL canopy reflectance model from AVIRIS equivalent spectra: theoretical study, Remote Sens. Environ. 44 (1993) 281-292.

[15] Jacquemoud S., Baret F., Andrieu B., Danson F.M., Jaggard K., Extraction of vegetation biophysical parameters by inversion of the PROSPECT + SAIL models on sugar beet canopy reflectance data. Application to TM and AVIRIS sensors, Remote Sens. Environ. 52 (1995) 163-172.

[16] Kimes D.S., Radiative transfer in homogeneous and heterogeneous vegetation canopies, in: Myneni R.B., Ross J. (Eds.), Photon-Vegetation Interactions, Springer-Verlag, Stuttgart, 1991, pp. 45-109.

[17] Li X., Strahler A.H., Woodcock C.E., A hybrid geometric optical-radiative transfer approach for modeling albedo and directional reflectance of discontinuous canopies, IEEE Trans. Geosci. Remote Sens. 33 (1995) 466-480,

[18] Myneni R.B., Williams D.L., On the relationship between FAPAR and NDVI, Remote Sens. Environ. 49 (1994) 200-211.

[19] Myneni R.B., Marshak A., Knyazikhin Y., Asrar G., Discrete ordinates method for photon transport in leaf canopies, in: Myneni R.B., Ross J. (Eds.), Photon-Vegetation Interactions, Springer-Verlag, Stuttgart, 1991, pp. 45-109.

[20] North P.R.J., Three-dimensional forest light interaction model using a Monte Carlo method, IEEE Trans. Geosci. Remote Sens. 34 (1996) 946-956.

[21] Peterson D.L., Aber J.D., Matson P.A., Card D.H., Swanberg N.S., Wessman C., Spanner M., Remote sensing of forest canopy and leaf biochemical contents, Remote Sens. Environ. 24 (1988) 85-108. 
[22] Pinel V., Gastellu-Etchegorry J.P., Sensitivity of texture of high resolution images of forest to biophysical and acquisition parameters, Remote Sens. Environ. 65 (1998) 61-85.

[23] Price J.C., Bausch W.C., Leaf area index estimation from visible and near-infrared reflectance data, Remote Sens. Environ. 52 (1995) 55-65.

[24] Sellers P.J., Berry J.A., Collatz G.J., Field C.B., Hall F.G., Canopy reflectance, photosynthesis and transpiration, III. A reanalysis using enzyme kinetics electron transport models of leaf physiology, Remote Sens. Environ. 42 (1992) 187-216.
[25] St-Onge B.A., Cavayas F., Estimating forest stand structure from high resolution imagery using the directional variogram, Int. J. Remote Sens 16:11 (1995) 1999-2021.

[26] Verdebout J., Jacquemoud S., Andreoli G., Hosgood B., Pedrini A., Schmuck G., A simple modelling approach to vegetation biochemistry spectroscopy in remote sensing, in: 'MAC Europe 91' Workshop, ESAWPP-88, Paris, 1995, pp. 149-159.

[27] Verhoef W., Light scattering by leaf layers with application to canopy reflectance modeling: the SAIL model, Remote Sens. Environ. 16 (1984) 125-141. 